\title{
A Comparative Study of the Levels of Statistical Competency among Post-Graduate Students of the Universities of Yemen and India
}

\author{
Mamun Ali Naji Qasem¹, Punita Govil², Swati Gupta ${ }^{2}$ \\ ${ }^{1}$ Faculty of Education, Ibb University, Ibb, Yemen \\ ${ }^{2}$ Department of Education, Aligarh Muslim University, Aligarh, India \\ Email: mamonbnaa@gmail.com, punita govil@rediffmail.com, swt21gupta@gmail.com
}

Received 21 January 2015; accepted 9 February 2015; published 13 February 2015

Copyright (C) 2015 by authors and Scientific Research Publishing Inc.

This work is licensed under the Creative Commons Attribution International License (CC BY). http://creativecommons.org/licenses/by/4.0/

\section{(c) (i) Open Access}

\section{Abstract}

The present study has been undertaken to evaluate the level of statistical competency of the post-graduate students belonging to the Faculty of Education in the Universities of Yemen and India. A standardized test prepared by the researchers has been used to assess the level of statistical competency of students. The study reveals that 1) The level of statistical competency of the post-graduate students belonging to the Faculty of Education in Universities of Yemen is average. 2) The level of statistical competency of the post-graduate students belonging to the Faculty of Education in Indian Universities is less than average. 3) The level of statistical competency of Yemeni post-graduate students is significantly higher than their counterparts of India. 4) There is a significant difference between male and female post-graduate students in the level of statistical competency. The male post-graduate students are better than female post-graduate students.

\section{Keywords}

Statistics, Statistical Competency, Parametric \& Non-Parametric Statistics

\section{Introduction}

Statistics plays a major role in scientific research. In other words, by using appropriate statistical tools, a re- 
searcher can make right decisions in terms of accepting and rejecting hypotheses based on his/her research. For doing this, the knowledge of different statistical terminology, symbols, concepts and analysis procedures in research is highly important. A researcher must be selective and choose an appropriate and required process for each kind of research so that the valid and reliable conclusions may be achieved.

Statistics has a unique role to play in the modern scientific researches. It has been believed that every study of any elevated phenomenon should include a statistical analysis, which will ultimately come out with certain remarks about the phenomenon or problem based upon factual figures [1].

Many researchers [2] [3] point out that the main reason of contradictory results in the field of psycho-educational sciences is the misusing of statistics and ignorance of accuracy during data analysis.

With the emerging importance of statistics and its multiple uses in the various fields of theoretical and applied knowledge, statistics is also included as a compulsory subject for the most faculty students as a part of their course work program, which enables the students to analyze the raw data by using an appropriate statistical method or technique. Thus, students at post-graduation level must have the knowledge to deal with such programs and be able to interact with the statistical aspects of life inside the classroom as well as outside the classroom [4].

In fact, it has become necessary for each post-graduate student to have competency in basic statistics that may help him to cope with the fast developments and rapid changes of the current era. In the past, research studies relied mainly on the traditional tests in which much concern was given to compare the individual performance to his peers without giving attention to identify the knowledge and competency of students. Contrary to that, now a days, research studies are carried out in most scientific manner. Knowledge of statistics plays a leading role in this regard. Therefore, it is necessary that every research scholar must be competent regarding the usage of statistics, so that most reliable and justifiable inferences may be drawn out for the population.

Accordingly, the present study aims at evaluating the statistical competency among post-graduate students in the Faculty of Education in the Universities of Yemen and India. The current research is of great importance because it aims at measuring the level of statistical competency of post-graduate students so if needed they may enhance their knowledge. It can also be supportive for those who are interested in the evaluation of statistical methods used in the fields of Humanities and Education. In addition, the sample community of this study is post-graduates who are actually going to be research scholar and would be directly involved in research activity, where the practical knowledge of statistics is necessary.

\section{Research Problems}

The current research is aimed at finding out the answers of the following questions:

1) What is the level of statistical competency among post-graduate students belonging to the Faculty of Education in the Universities of Yemen?

2) What is the level of statistical competency among post-graduate students belonging to the Faculty of Education in Indian Universities?

3) Is there any difference between the levels of statistical competency of post-graduate students belonging to the Faculty of Education in the Universities of Yemen and India?

4) Is there any difference between the levels of statistical competency of post-graduate students according to the variable "gender"?

\section{Research Objectives}

The present study aims at achieving the following objectives:

1) To identify the level of statistical competency among post-graduate students belonging to the Faculty of Education in Yemeni Universities.

2) To identify the level of statistical competency among post-graduate students belonging to the Faculty of Education in Indian Universities.

3) To identify the difference between the levels of statistical competency of post-graduate students belonging to the Faculty of Education in the Universities of Yemen and India.

4) To identify the difference between the levels of statistical competency of post-graduate students according to the variable "gender". 


\section{Definition(s) of Terms}

The following paragraphs describe the operational definitions of key terms used in the study:

\subsection{Statistics}

Linguistically, statistics means comprehensive counting. Modern dictionary of Sociology (Achilles and George Theocorson) introduces statistics as "a set of methods or tools used for collecting, classifying, categorizing, demonstrating, and analyzing quantitative data" [1]. The most common definition of statistics is that "it includes maths and relies upon calculation of numbers, how the numbers are selected and how the statistical results are interpreted" [5]. However, the term "statistical method" used by the researchers here, refers to those descriptive and deductive methods, which are used by the investigators working on various courses at post-graduation and research level in the Faculty of Education in the Universities of Yemen and India.

\subsection{Statistical Competency}

American Statistical Association (ASA) [6] defined statistical competency as the student's ability to collect, organize, describe, understand and evaluate the statistical data, in addition to his/her ability to solve problems through statistical identification and application of appropriate statistical methods [7] [8]. Here, the term "statistical competency" refers to a set of knowledge, abilities and proficiency in the field of educational statistics, which should be possessed by the post-graduate students and they should be able to apply statistical measures effectively and proficiently in the field of Education.

\section{Delimitations of the Study}

The present study is limited to evaluate the statistical competency among post-graduate students belonging to the Faculty of Education in Universities of Yemen and India. The students, who have been selected for the courses of statistics are supposed to have the required statistical competency, which enable them to deal with the different types of statistical measures regarding data analysis and evaluation.

\section{Methodology}

The descriptive survey method is a common approach used in the field of social and human sciences. It carefully records and observes a certain phenomenon or problem for certain period(s) of time with the purpose of exploring such problem in terms of content and characteristics to attain certain conclusions and generalizations, which can help to understand the current problem \& situation and to improve it [9]. This method has been used for achieving the major objective of the research "evaluating the level of statistical competency among the postgraduate students of the Universities of Yemen and India”.

\section{Research Population and Sample}

Research population includes all post-graduate students of the Faculty of Education in the University of Yemen and India. A sample of 191 post-graduate students has been selected by using simple random sampling technique. Table 1 describes the research sample:

\section{Research Tool}

The current research aims to evaluate the level of statistical competency among the post-graduate students of the Table 1. Research sample.

\begin{tabular}{ccccc}
\hline University & Male & Female & Total \\
Yemen & 55 & 65 & 120 \\
India & 18 & 53 & 71 \\
Total & 73 & 118 & 191 \\
\hline
\end{tabular}


Faculty of Education. For the purpose, a standardized test of statistical competency [10] has been used to measure their level of statistical competency. The test has good content validity, construct validity and discrimination validity. The reliability of the test was evaluated by calculating Alpha Cronbach Coefficient that is 0.89 . The test consists of 60 items related to seven dimensions of statistical competency.

Table 2 indicates that there are seven dimensions of statistical competency and efficiency in all dimensions comprises statistical competency that is necessary for post-graduate students.

\section{Results \& Discussion}

To analyze the data, first of all it was checked out whether the data is normal or not. For checking the normality of data Kolmogorov-Smirnov and Shapiro-Wilk tests have been used.

\begin{tabular}{|c|c|c|c|c|c|c|}
\hline \multicolumn{7}{|c|}{ Tests of Normality } \\
\hline \multirow{2}{*}{$\mathrm{N}$} & \multicolumn{3}{|c|}{ Kolmogorov-Smirnov } & \multicolumn{3}{|c|}{ Shapiro-Wilk } \\
\hline & Statistic & $\mathrm{df}$ & Sig. & Statistic & df & Sig. \\
\hline 191 & 0.78 & 191 & 0.06 & 0.987 & 191 & 0.066 \\
\hline
\end{tabular}

The table given above reveals that both the values (Kolmogorov-Smirnov 0.78 and Shapiro-Wilk 0.987) are not significant at 0.05 level. It implies that the data is normally distributed and appropriate for applying parametric statistics. The below given graph clearly presents that the data is normally distributed.

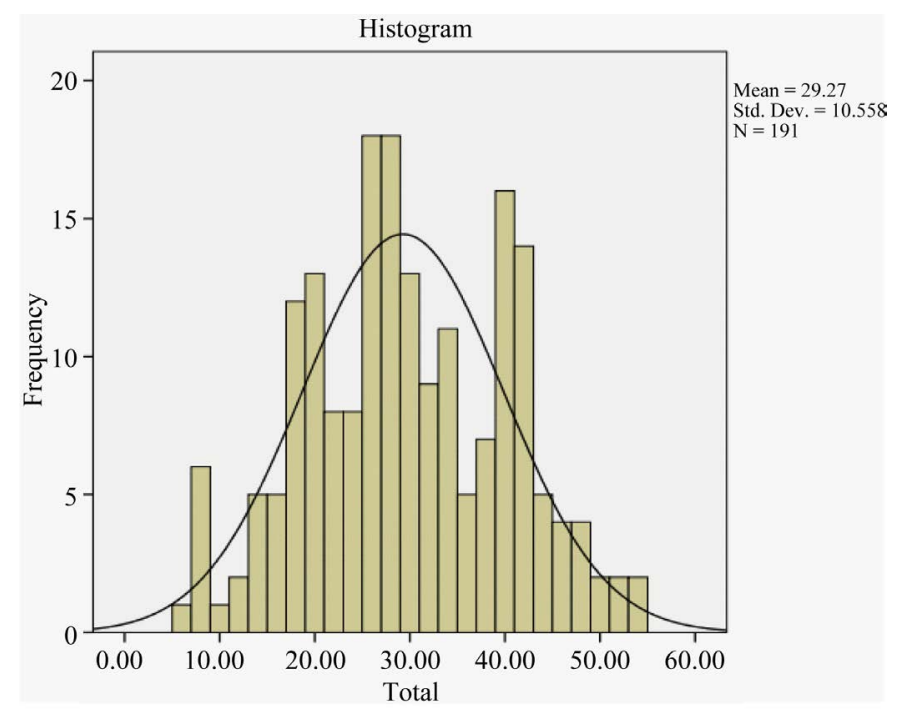

Table 2. Dimensions of statistical competency test.

\begin{tabular}{ccc}
\hline Number & Competency & Number of items \\
\hline Dimension (one): & Understanding of basic statistical concepts & 13 \\
Dimension (two): & Interpretation of descriptive statistics & 11 \\
Dimension (three): & Measuring \& interpreting the coefficient of correlation & 10 \\
Dimension (four): & Use of various parametric methods & 7 \\
Dimension (five): & Use of various non-parametric methods & 5 \\
Dimension (six): & Explaining the results given by the statistical programs as SAS, SPSS etc. \\
Dimension (seven): & Selecting the appropriate statistical method in accordance with problems & 6 \\
Total & & 60 \\
\hline
\end{tabular}


The following paragraphs present the analysis of data according to the objectives.

Objective No. 1: To identify the level of statistical competency among post-graduate students belonging to the Faculty of Education in the Universities of Yemen.

The inferential statistics t-test for one-sample has been applied to measure the level of statistical competency among the post-graduate students belonging to the Faculty of Education of Universities of Yemen, where, assumed mean $=$ minimum score of the items + maximum score of the items $/ 2([0+60] / 2=30)$.

It is clear from Table 3 that the mean score of the sample is 30.91 i.e. an average post-graduate student belonging to the Faculty of Education in the Universities of Yemen is able to secure 51.52\% scores on statistical competency test. The standard deviation is 10.03 for statistical competency. The standard deviation describes how well the mean represents the data i.e. how much the data can deviate from the mean. Here, the value shows that on an average the data can deviate 10.03 from the mean value. The assumed mean is 30 . It means that a statistically competent student should secure a score of 30 on the test.

The " $\mathrm{t}$ " value is 0.992 , which is not significant. Thus, it can be concluded that there is no difference between the real mean and assumed mean in the level of statistical competency of post-graduate students belonging to the Faculty of Education in the Universities of Yemen. It also indicates that the level of statistical competency of post-graduate students belonging to the Faculty of Education in the Universities of Yemen is average. Figure 1 clearly depicts the real mean and assumed mean of post-graduates belonging to the Faculty of Education in the Universities of Yemen.

Objective No. 2: To identify the level of statistical competency among post-graduate students belonging to the Faculty of Education in Indian Universities.

To know the level of statistical competency among post-graduate students of the Faculty of Education in Indian Universities, the inferential statistics "t" test for one sample has been applied, where, assumed mean = minimum score of the items + maximum score of the items $/ 2([0+60] / 2=30)$.

Table 4 indicates that the mean score of the sample is 26.49 with s.d. 10.91 i.e. an average post-graduate student belonging to the Faculty of Education in the Universities of India is able to secure $44.15 \%$ scores on statistical competency test. The standard deviation shows that the data can deviate 10.91 from the mean value. The assumed mean is 30 i.e. a statistically competent student should secure a score of 30 on the test. The "t" value is 2.71 , which is significant. Thus, it can be said that there is difference between the real mean and assumed mean in the level of statistical competency of post-graduate students belonging to the Faculty of Education in Indian Universities. It also indicates that the level of statistical competency of the post-graduate students belonging to the Faculty of Education in Indian Universities is less than average. Figure 2 clearly depicts the real mean and assumed mean of post-graduates belonging to the Faculty of Education in Indian Universities.

Objective No. 3: To identify the difference between the levels of statistical competency of post-graduate students belonging to the Faculty of Education in the Universities of Yemen and India.

To know the difference between the levels of statistical competency of post-graduate students belonging to the Faculty of Education in the Universities of Yemen and India, the inferential statistics test t-test for two independent samples has been applied.

Table 3. Descriptive statistics related to the level of statistical competency among post-graduate students belonging to the Faculty of Education in the Universities of Yemen.

\begin{tabular}{cccccccc}
\hline $\mathbf{N}$ & Real Mean & Test Value (Assumed mean) & s.d. & df & Level of Sig. \\
\hline 120 & 30.91 & 30 & 10.03 & 119 & 0.992 \\
\hline
\end{tabular}

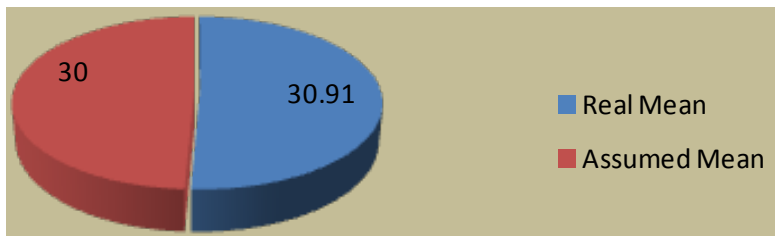

Figure 1. Distribution of real mean and assumed mean of postgraduates belonging to the Faculty of Education in the Universities of Yemen. 
Table 4. Descriptive statistics related to the level of statistical competency among post-graduate students belonging to the Faculty of Education in Indian Universities.

\begin{tabular}{ccccccc}
\hline $\mathbf{N}$ & Real Mean & Test Value (Assumed Mean) & s.d. & df & Level of Sig. \\
\hline 71 & 26.49 & 30 & 10.91 & 70 & 2.71 \\
\hline
\end{tabular}

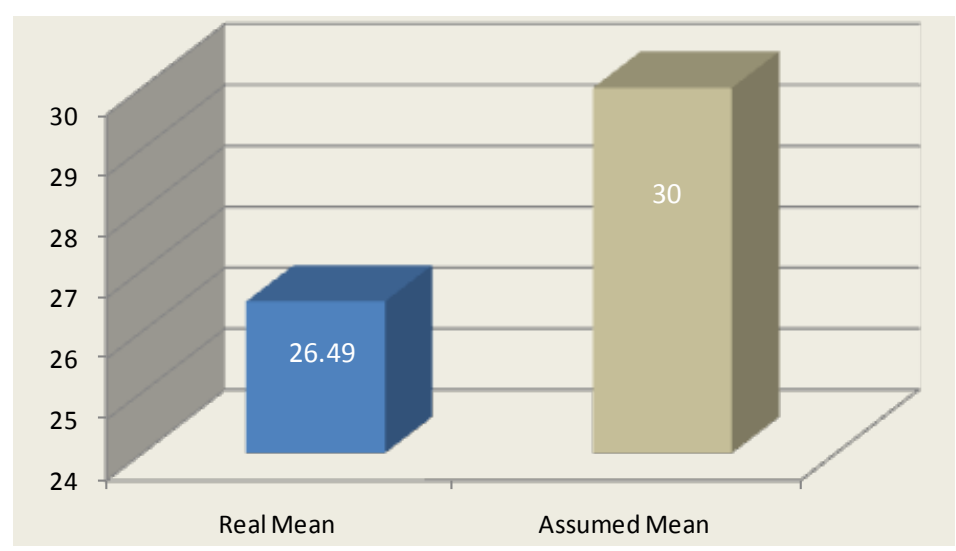

Figure 2. Distribution of real mean and assumed mean of post-graduate students belonging to the Faculty of Education in Indian Universities.

Table 5 reveals that the mean score of Indian students is 26.49 and of the Universities of Yemen is 30.91. It indicates that an average post-graduate student belonging to the Faculty of Education in the Universities of India is able to secure $44.15 \%$ score on statistical competency test while an average post-graduate student belonging to the Faculty of Education in the Universities of Yemen is able to secure $51.52 \%$ score on statistical competency test. The standard deviation for statistical competency of Indian students shows that the data can deviate 10.91 from their mean value while for Yemeni students it can deviate 10.03 from their mean value. The " $\mathrm{t}$ " value is 2.85 at the level 0.05 , which shows that there is significant difference between the levels of statistical competency of the students belonging to the Faculty of Education of the Universities of Yemen and India. It can be concluded that the level of statistical competency of post-graduate students belonging to the Faculty of Education in the Universities of Yemen is higher than Indian students. Figure 3 clearly depicts the mean scores of post-graduates belonging to the Faculty of Education in the Universities of India and Yemen.

Objective No. 4: To identify the difference between the levels of statistical competency of post-graduate students according to the variable "gender" (male \& female).

To know the difference between the levels of statistical competency of post-graduate students according to the variable gender (male \& female), the inferential statistics "t-test" for two independent samples has been applied.

Table 6 shows that the mean value of male post-graduates is 31.45 and of female post-graduates is 27.92 i.e. an average male post-graduate student belonging to the Faculty of Education in the Universities of India and Yemen is able to secure $52.42 \%$ score on statistical competency test while an average female post-graduate student belonging to the Faculty of Education of both Universities is able to secure $46.53 \%$ score on the test. The standard deviation of male post-graduate students on statistical competency is 9.69 i.e. the data can deviate 9.69 from the mean value and standard deviation of female post-graduates on the test is 10.88 that means that the data can deviate 10.88 from their mean value. The " $t$ " value is 2.27 , which is significant at 0.05 level. Thus, it can be concluded that there is a significant difference between male and female post-graduates in the levels of statistical competency and male post-graduate students belonging to the Faculty of Education of both countries are better than their female counterparts. Figure 4 clearly depicts the mean scores of male and female post-graduates belonging to the Faculty of Education in the Universities of India and Yemen.

Discussion: The concept of statistical competency is very important for those students who desire to get admission in doctoral courses or applying for fellowship programs. Statistical competency in behavioral sciences and more specifically in Education and Psychology is a necessary component. Most of the research studies (except theoretical research) require knowledge of statistics to implement the results of the studies. Besides, knowledge of statistics in behavioral sciences is important to draw inferences from ethnographic and demographic 
Table 5. Descriptive statistics related to the levels of statistical competency of post-graduate students belonging to the Faculty of Education in the Universities of Yemen and India.

\begin{tabular}{ccccccc}
\hline Sample & $\mathbf{N}$ & Mean & s.d. & df & t & Level of Sig. \\
\hline India & 71 & 26.49 & 10.91 & \multirow{2}{*}{189} & 2.85 & 0.05 \\
Yemen & 120 & 30.91 & 10.03 & & & \\
\hline
\end{tabular}

Table 6. Descriptive statistics related to the levels of statistical competency of male and female post-graduate students belonging to the Faculty of Education.

\begin{tabular}{cccccc}
\hline Sample & N & Mean & s.d. & df & Level of Sig. \\
\hline Male & 73 & 31.45 & 9.69 & 189 & 2.27 \\
Female & 118 & 27.92 & 10.88 & 0.05 \\
\hline
\end{tabular}

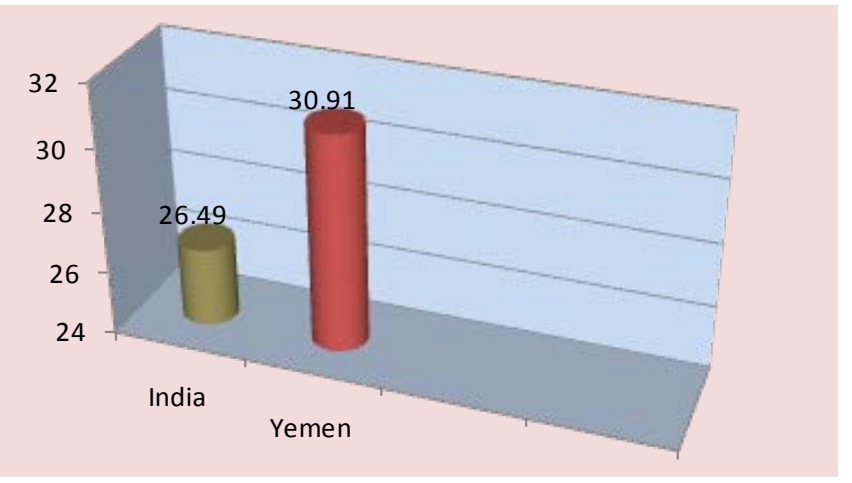

Figure 3. Distribution of mean scores of post-graduates belonging to the Faculty of Education in the Universities of Yemen and India.

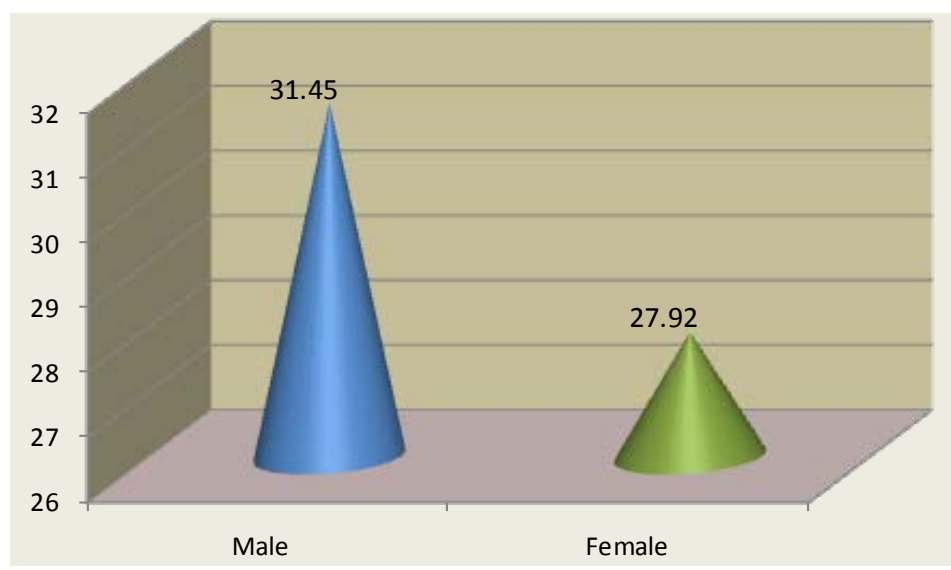

Figure 4. Distribution of mean scores of male and female post-graduates belonging to the Faculty of Education in the Universities of Yemen and India.

data. The present paper describes level of statistical competency among post-graduate students, which has been found even below than average. Low competency in statistics is directly going to affect the quality of research output in education. Thus, the present study emphasizes the need to make additional provisions for students at post-graduation level so that their comprehension and skill related to statistics may be enhanced. There is the need to upgrade and revise the syllabus at graduation level also so that learners may have required previous knowledge. Analysis of data and its interpretation is an important and inevitable part of any research study and 
requires statistical competency.

\section{Conclusions}

The study has resulted in the following conclusions:

1) The level of statistical competency among post-graduate students belonging to the Faculty of Education in the Universities of Yemen is average.

2) The level of statistical competency among post-graduate students belonging to the Faculty of Education in Indian Universities is less than average.

3) There is statistically significant difference between post-graduate students belonging to the Faculty of Education in the Universities of Yemen and India in the levels of statistical competency. Post-graduate students belonging to the Universities of Yemen are better than their Indian counterparts.

4) There is a significant difference between male and female post-graduate students in the levels of statistical competency belonging to the Faculty of Education of both the countries. Male post-graduate students are better than female post-graduate students of both countries.

\section{References}

[1] Al-Kassas, M.M. (2007) Principles of Statistics and Social Measurement. Almansorah University Press, Almansorah.

[2] Al'assaf, S.A. (1995) An Introduction to Research in Behavioural Sceinces. Alobaikan Bookstore, Riyadh.

[3] Al-Dawsry, E. M. (2001) A Reference Guide for Educational Evaluation. 3rd Edition, Arabian Education Department of Gulf Countries, Riyadh.

[4] Rian, A.A. (2008) Tests and Measurements in Psychological and Educational Sciences. Modern Dar Alketab, Cairo.

[5] Lane, M. (2009) E-Statistics Education: A Multimedia Course of Study. http://onlinestatbook.com/Online_Statistics_Education.pdf

[6] APA (2010) Publication Manual of the American Psychological Association. 6th Edition, American Psychological Association, Washington DC.

[7] Audah, A. and Alkhalily, K.Y. (1988) Statistics for a Researcher in Education and Humanties Sciences. Dar Alfekr Publishers, Amman.

[8] AbuHashem, A.M. (2004) The Statistical Guide in Analyzing Data Using SPSS. Al-Roshd Bookstore Publishers, Riyadh.

[9] Alian, P.M. (2001) Scientific Research, Methods and Procedures. International House of Ideas, Jordan.

[10] Qasem, M.A., Govil, P. and Gupta, S. (2014) Statistical Competency Test. Agra Psychological Cooperation, Agra. 
Scientific Research Publishing (SCIRP) is one of the largest Open Access journal publishers. It is currently publishing more than 200 open access, online, peer-reviewed journals covering a wide range of academic disciplines. SCIRP serves the worldwide academic communities and contributes to the progress and application of science with its publication.

Other selected journals from SCIRP are listed as below. Submit your manuscript to us via either submit@scirp.org or Online Submission Portal.
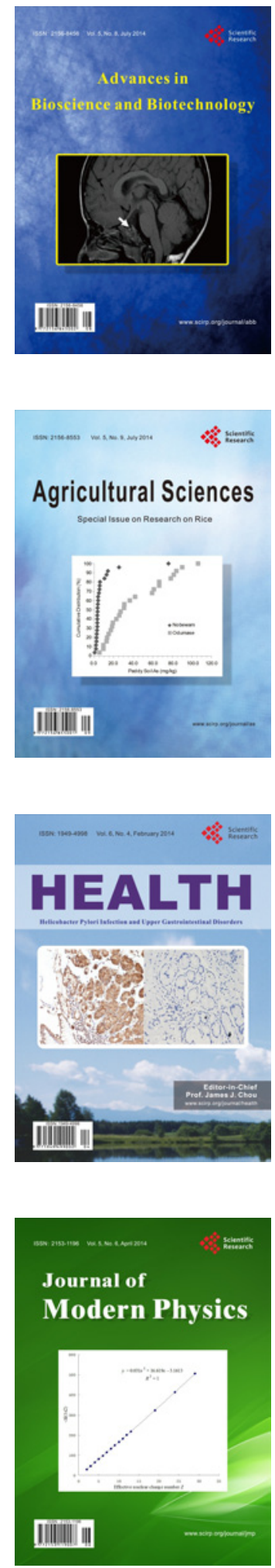
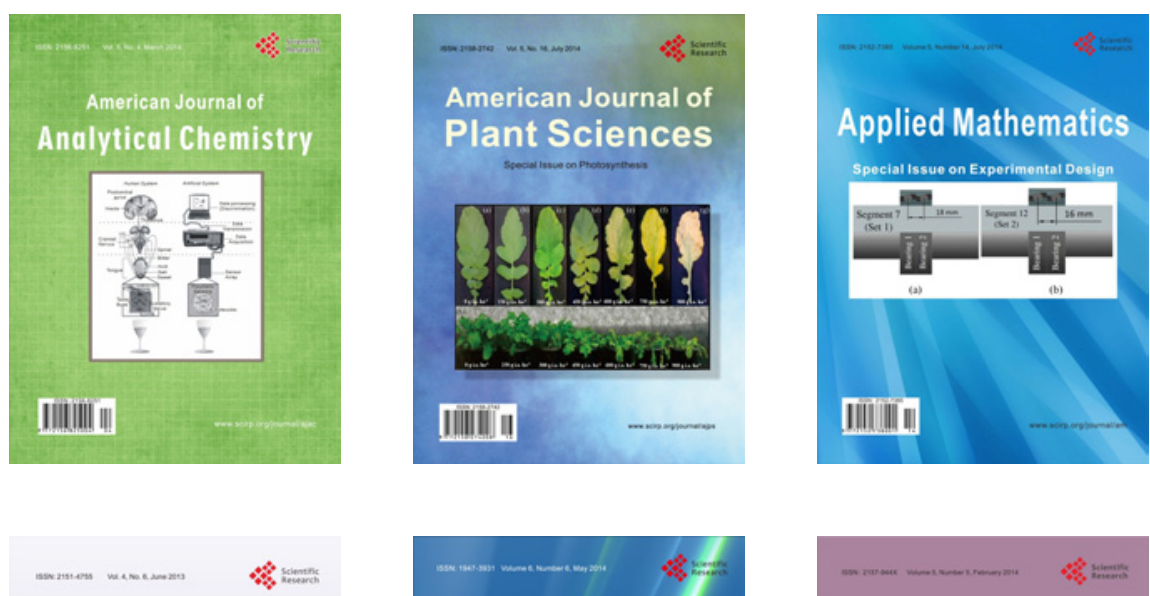

Creative Education
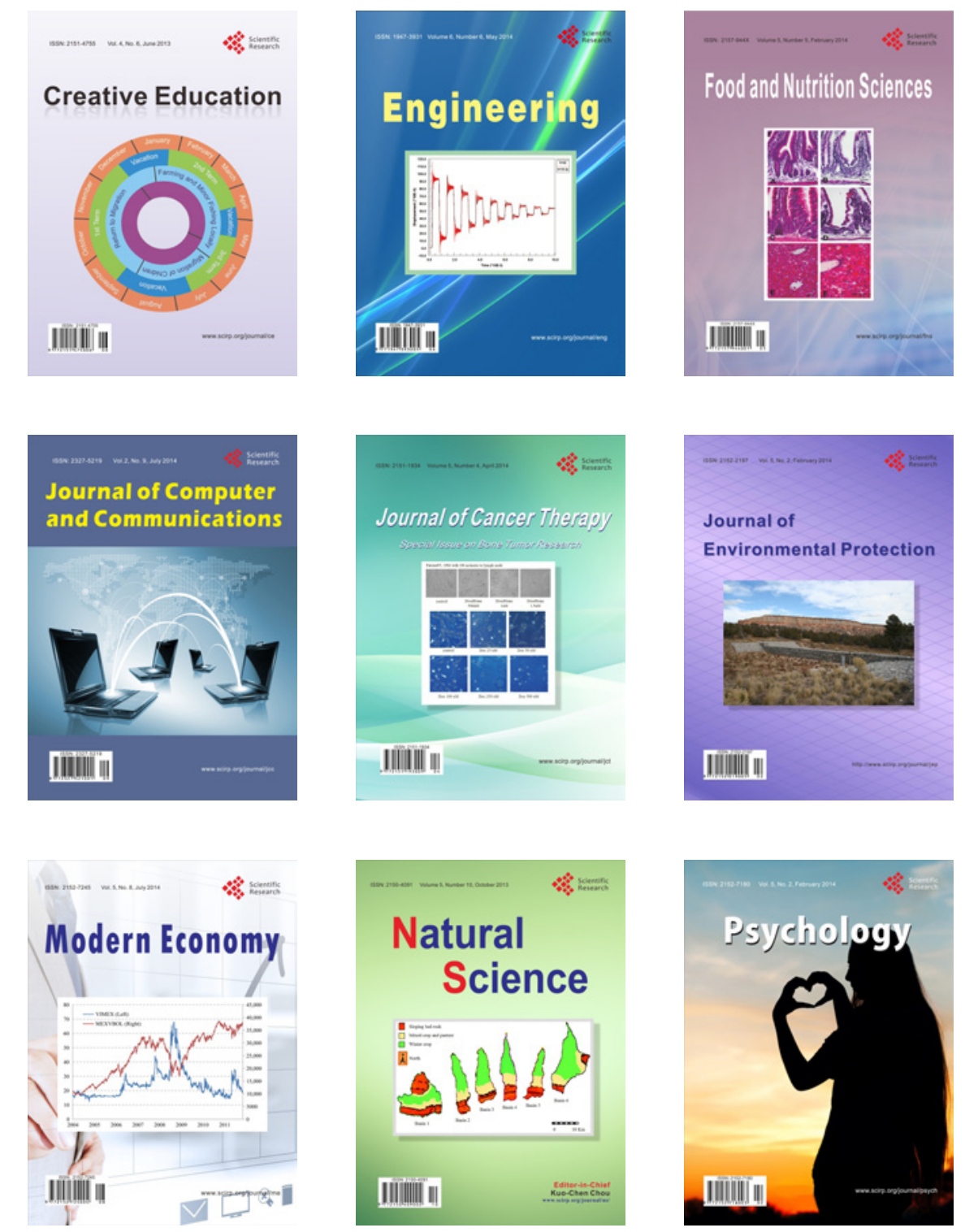